Elsevier required licence: (C2017. This manuscript version is made available under the CC-BY-NC-ND 4.0 license http://creativecommons.org/licenses/by-nc-nd/4.0/ 
TITLE: Living with multiple losses: Insights from patients living with pressure injury

RUNNING TITLE: Pressure injury associated loss

Debra E Jackson RN PhD ${ }^{123}$, Lisa A Durrant PhD ${ }^{4}$, Marie Hutchinson RN PhD 5 , Charlotte A Ballard $\mathrm{BA}^{6}$, Stephen Neville RN PhD ${ }^{7}$, Kim Usher RN PhD ${ }^{8}$

${ }^{1}$ Professor, Director of Oxford Institute for Nursing, Midwifery \& Allied Health Research (OxINMAHR), The Colonnade, Oxford Brookes University, Oxford, UK.

djackson@brookes.ac.uk (corresponding author).

${ }^{2}$ Professor, Oxford University Hospitals NHS Foundation Trust, Oxford, UK.

${ }^{3}$ Professor of Nursing, University of Technology, Sydney, Australia.

${ }^{4}$ Project Manager, OxINMAHR, Oxford Brookes University, Oxford, UK.

I.durrant@brookes.ac.uk

${ }^{5}$ Associate Professor, Southern Cross University, Lismore, New South Wales, Australia. Marie.Hutchinson@scu.edu.au

${ }^{6}$ Research Intern, OxINMAHR, Oxford Brookes University, Oxford, UK.

cballard@brookes.c.uk

${ }^{7}$ Associate Professor, Auckland University of Technology, Auckland, New Zealand.

stephen.neville@aut.ac.nz

${ }^{8}$ Professor, University of New England, Australia.

kusher@une.edu.au

Conflict of Interest: The authors declare that they have no conflict of interest. 


\section{TITLE: Living with multiple losses: Insights from patients living with pressure injury}

\section{RUNNING TITLE:}

Pressure injury associated loss

\section{ABSTRACT:}

Background: Pressure injury is a common problem. Its prevention and treatment is predominantly focussed on views, perceptions and knowledge of healthcare staff rather than on patient experience, particularly those patients living in their own homes.

Aim: This paper reports findings on patients experiences and perceptions of loss associated with PI. These findings are drawn from a larger study of pressure injury patients living and receiving care in the community.

Methods: Qualitative interviews with 12 participants with pressure injury and five carers. Data was audio recorded and thematically analysed. The study is reported in accordance with the COREQ guidelines.

Findings: Having a pressure injury negatively affected many aspects of life for our participants resulting in multiple losses. These losses included loss of mobility and independence, privacy and dignity, and social engagement and ability to engage in preferred activities.

Discussion: Although the effects of a pressure injury may be similar for many people, the most important issues will differ from person-to-person thus treatment and prevention of pressure injury requires a multidisciplinary team having a holistic care approach. Some patients' pressure injury will never heal and it is increasingly important to involve the patient to find out what matters most to them and how their wound is impacting on them, to jointly develop a holistic, person-centred plan.

Conclusion: Policy and practice should recognise and reflect that patients living with a pressure injury at home have different challenges and needs to those in acute or long term care. Pragmatic solutions in the delivery of pressure injury care are needed to compliment the drive to move healthcare from the hospital-to-home. 


\section{SUMMARY OF RELEVANCE:}

Issue

Little is known about the impact of pressure injuries on the lives of patients living in their own homes, especially from the patient's perspective.

\section{What is Already Known}

Chronic pressure injuries are predicted to rise in community settings as healthcare moves from hospital-to-home. Solutions for the management of chronic pressure injuries at home are currently lacking.

\section{What this Paper Adds}

Pressure injury patients at home experience loss in mobility and independence, privacy and dignity, and social interaction. These losses are long-term and life changing, and should be acknowledged and incorporated into holistic care solutions, planning and management.

\section{INTRODUCTION:}

A pressure injury (PI), also termed a pressure ulcer is defined as a localised injury to the skin and/or underlying tissue, usually over a bony prominence, as a result of pressure, or pressure in combination with shear (1). These injuries disproportionately affect the older population and impose considerable morbidity and mortality on millions of adults $(2,3)$. Despite the fact that $\mathrm{PI}$ is a common problem, there is a distinct lack of evidence stemming from patients' perspectives, and even less so within the community environment (4). Studies tend to focus more on the views of 
healthcare staff about their experience and knowledge of PI prevention and treatment (5); and to date there has been little room for patients to explain how a PI has affected them personally, how they would like their treatment to work and which PI related issues they want addressed. In this paper we report findings on patients perceptions of loss associated with PI. These findings are drawn from a larger study that sought to gain insights into the experiences and perceptions of life with a PI from patients living and receiving care in the community.

\section{LITERATURE REVIEW:}

The cost to the patient of living with a PI is significant, and impacts on physical, social and psychological scopes of life $(6,7)$. Patients report pain, malodour and exudate, social isolation, reduced independence and reduced mobility $(8,9)$ all of which delay rehabilitation and impact both on patients and their families (9). Reduced physical activity and depression stemming from PI are inextricably linked and have been referred to as the 'inactivity trap' (11). Combined with advanced age, malnourishment and co-morbidities, Pls can make it difficult for people to partake in their usual activities, both within and outside their homes (12). Psychologically, PI can manifest in stress, negative emotions, and a reduced quality of life $(13,14,6)$. The anticipation of pain associated with PI have been shown to lead to negative mood and anxiety (15).

PI research has traditionally focussed on issues such as risk factors and characteristics (16), estimating prevalence and incidence, and economic costs (17); much less evidence surrounds the experiences of actually living with a PI. There have been a number of studies examining the experience of living with a chronic wound, in the main these studies have explored venous leg ulcers 18). However, though scant, extant literature has described high rates of depression amongst community dwelling PI patients compared to matched controls without PI (19). Exploring PI experiences through surveys $(19,20)$, patient reported outcome measures (PROMS) (21) and 
specifically designed quality of life questionnaires (22) have been valuable, but also highlighted the lack of patient voice in the literature. A few studies have explored the experiences of living with a PI in depth and gleaned valuable information (10), however, none of these have focused specifically on loss.

\section{Aim of this paper}

This paper is drawn from a larger concurrent, mixed-methods case study that sought to gain insights into the experiences and perceptions of life with a PI living in a community bounded by a single postcode area. Using storied accounts from patients collected in 2016 and retrospective quantitative information from 2015 medical records, a detailed view of PI was produced from a case study region. Findings pertaining to service use and consistency of care (4), and experiences of pain are reported elsewhere (23). In this current paper, we report on loss as it is lived and experienced by people living with a PI.

\section{PARTICIPANTS, ETHICS \& METHODS:}

In an ethically approved study (UK National Research Ethics, 16/NE/0075, $26^{\text {th }}$ February 2016), adult patients from two UK National Health Service (NHS) Trusts were considered eligible if they; (i) were receiving or just received medical care for $\mathrm{PI}$, (ii) had the mental capacity to understand the written study information and provide informed consent and (iii) the capability to complete a short questionnaire and participate in a qualitative interview. Direct care-teams (hospital tissue viability nurses, community district nurses, podiatrists) identified and provided study information to a convenience sample of 36 eligible patients between May-October 2016. Reasons for nonparticipation were not recorded due to the voluntary nature of recruitment. 
Thirteen patients replied directly to the research team to offer their participation in the study. Of these, one patient was excluded from analysis in this sub-study as they had a recent hospital acquired $\mathrm{PI}$ and no experience of the challenges of living with a $\mathrm{Pl}$ at home. Participants were consented to the study with the addition of five family members or carers with appropriate approvals. Eleven patients ( 5 with their carer/family member present) were living at home in the community with care provided by district nurses, one patient was hospitalised for medical reasons other than $\mathrm{PI}$ at the time of recruitment and interview, but had considerable experience of PI care at home. Demographically, participants represented a diverse pool with 9 females, ages 31-92 and PI categorised from 2-4 (1). All patients completed a short quality of life questionnaire (EQ5D-5L, with permission from EuroQol) prior to a semi-structured interview to inform the interviewer of potential themes.

Interviews were undertaken in patients own homes $(n=9)$ or single hospital rooms $(n=3$; one inpatient and two to coincide with outpatient appointments) in English, without the need of an offered translation service. Interviews were conducted by a post-doctoral female registered health professional $(\mathrm{xx})$ who had no prior contact or caring responsibilities for any of the participants. Semi-structured interviews, guided by questions devised by the research team and a patient advisor with personal experience of $\mathrm{PI}$, were audio-recorded with permission, and lasted an average of 37 minutes (range 16-69 minutes). Interviews were transcribed and all participants opted to receive a summary of results on completion of the study. Verbatim transcripts underwent thematic content analysis by three experienced researchers (DJ, LD, KU) and interviews ceased when no new themes were emerging (24). The thematic analysis process as set out by Braun and Clarke (25) was used by the researchers. The three steps involve: (1) transcription - the data were transcribed from narratives; (2) coding - each data item was coded to be thorough and comprehensive; and (3) analysis - data were interpreted and made sense of rather than just paraphrased or described.

\section{Rigour}


Rigour is addressed in the current project through various strategies including member-checking through a member of our patient advisory group; credibility, through audiotaping of interviews with prompt transcription and the provision of excerpts of narratives to support the emergent understandings and ongoing reflexive processes among the team; and dependability through a process of detailed description of decision-making processes and adherence to methodological principles $(26,27)$.

\section{FINDINGS:}

Having a PI negatively affected many aspects of life for our participants and loss came through as a clear theme in all of the participant interviews. They experienced multiple losses as a result of their $\mathrm{PI}$, and these losses included loss of mobility and independence, privacy and dignity, and social engagement and ability to engage in preferred activities. These are elaborated below.

\section{Loss of mobility and independence}

All participants expressed a loss of mobility associated with their PI. Loss of mobility diminished the participant's ability to continue with normal aspects of their lives, such as cooking a meal for themselves or simply moving about their own homes, and for those able to leave their homes, challenges with transport that deterred them from going out, impacting on activities such as shopping.

For most participants, standing and mobilising were significantly impeded. Participant 8 commented, 'I can't do as much, you know, walking or standing'. Participants were determined to remain as mobile as they could and so used mobility aids where possible.

I couldn't walk. I tried to walk with the walking frame, but then I was putting pressure on my heel. What I do is get two sticks.... Everywhere you go...stick (participant 6). 
Having a PI caused the participants to think of themselves differently. Previously they had seen themselves as strong and able-bodied; however, these perceptions were now altered. Participant 12 described having a PI being 'very handicapping', and participant 9 had come to think of herself as being 'disabled', with all the losses that entails:

I used to be very active, strong as a bull. Now, I've got to be honest with you, I'm virtually disabled [because of PI]. I make no bones about it (participant 9).

For participants engaged in paid employment the mobility issues that arose as a result of their PI impeded their working life.

When I'm in my work boots I'm walking very slow and laboured. You could tell I've got a mobility problem. People say to me for God's sake why don't you retire? Why don't you call it quits? ... I don't have a pension, I don't have big pension coming to me. If I were to leave I'd just go back on the dole. I'd be on the dole (participant 5).

Participant 5 felt the mobility problems were severe and would be with him for the rest of his life:

I think I'm always going to have issues with walking for the rest of my life. I know that however much I try, it's one of those things, I'm reluctant to say this, because however no matter how I try ... it's always going to be wrong with that foot (participant 5).

Not only were participants unable to stand and walk as they had previously, transport options also became limited, 'It affect me a lot in me walking and in trying to ride me (mobility) scooter. To get on and get off was bloody murder... Bloody horrible'(participant 6). Getting in and out of a car was also very difficult for many participants, especially those with PI on the sacrum or buttocks.

I can get into the car I can sit in the car, but wow, it hurts like hell getting in. As you get in the car you put your bottom in then swivel and get your legs in or heave yourself up. That's very, very difficult with a pressure sore.... very, very difficult with a pressure sore, general mobility (participant 12). 
Reduced mobility rendered patients reliant on others including family, partners, carers and healthcare professionals, and this caused distress and emotional conflict arising from such reliance, grateful for help from friends but disliking not being able to make independent choices. Participants described a loss of independence and a need to space and change their way of approaching activities that had previously been unproblematic:

I can hobble around, I know my limits. I was worried at trying to walk on it too much... the heel is bad so I try to walk on it like that and it is bloody murder. I mean I screamed. Look here, I hold onto this and once I get to me cooker, stand up here (participant 6).

Participants struggled with needing to ask for help, feeling they were a burden and not wanting to bother other people, 'you just wish you could do things yourself' (participant 12). There was an increasing need for help with a range of activities of daily living - activities they had previously managed independently:

I'm a very independent person, all my life and I find it very hard ... a couple of people do my shopping for me round here. .. I do hate people doing my shopping for me. Cos, I'm grateful for what they do, but it's not the same as doing your own. They never bring exactly what you want if you know what I mean. I can't see what's in the shops and I just rely on what's there and what they bring. I'm grateful of them doing it, of course I am, but it's not the same as going and having a little look yourself (participant 4).

\section{Loss of privacy and dignity}

Having a PI threatened personal privacy and dignity. Needing more help with personal care and hygiene activities meant that participants had come to require the presence of others to attend to matters that had previously been undertaken in private. Participant 9 had a PI on his heel and this 
meant that in addition to his issues with standing and walking, he needed some assistance with personal care, including with showering and dressing.

It's a bit awkward getting shoes on, but occasionally if I'm desperate for a shower there's these bags where you can tie it round your foot and can keep the dressing dry. But that's a lot of palaver (participant 9).

Participants reported threats to their dignity associated with requiring intimate care. Reflecting on her need for help with some aspects of intimate care, participant 11 described feeling 'humiliated' and 'upset'. Some participants struggled to have to accept intimate care from a person of the opposite gender.

The one thing I found very difficult to start with were the male carers, but I'm used to it now... You felt a little bit degraded but then you think hell it's got be done, what's dignity any more. You lose your dignity... (participant 12).

Dignity was also threatened because of odour arising from the PI. A carer describes the difficulties in dealing with the malodorous leakage from the $\mathrm{PI}$, and how she tried to manage this.

It gets a little bit wiffy, do you know what I mean? ... It has leaked through, when it's really bad, it has leaked. I just put another layer on the top, sometimes, just to stop, try and stop the smell and also, you can't see it, it looks bad, do you know what I mean? (carer of participant 2).

\section{Loss of social engagement and ability to engage in preferred activities}

Previously enjoyed activities were no longer possible for many participants, putting them at risk of social isolation. Participant's social interactions were considerably reduced because they had become house and even bed-bound. Participant 12 reported, 'Well I was stuck in bed I couldn't get out of bed here for a while'. Participant 4 commented, 'I haven't been out at all, not since last November', which was a period of eight months prior to participation in the study. The duration of 
the PI meant these problems were longer rather than short term, affecting the ability of participants to go out and socialise with others, over long periods; 'I don't really have a social life' (participant 9), and reflecting on his situation, participant 6 commented 'I have no life'. Concerns about wound leakage and odour also contributed to participants being socially isolated. Participant 2 commented that shame and embarrassment caused by the odour coming from her PI affected her going out and engaging in social activity.

Basically, I won't go out and I don't want to go out with, you know ... just the smell, because of the smell. If the smell wasn't there, it wouldn't have bothered me whatsoever. I'd just go out, you know (participant 2).

In addition to the losses around social engagement, participants were no longer able to engage in their preferred activities and pastimes. Some participants expressed a sense of loss about not being able to enjoy the outdoors any longer, participant 6 commented, 'I get depressed because I am not an indoor person'. Participant one had particularly enjoyed being out in the rural environment. However, though her family would have been pleased to take her on outings, she could no longer enjoy this because of mobility impairment associated with her PI.

We have to consider carefully what we're doing and where we're going. We can't get out into the hills or woods or anything like that (participant 1).

\section{Loss of control and personal autonomy}

Participants experienced a loss of control and personal autonomy over aspects of their daily lives. Participant 12 commented that 'the one thing about it is the pressure sore is in control and I am not'. For participant 12 , the sense that the PI was controlling her was exacerbated by the fact she could not see the injury. She reflected on whether being able to actually see the PI might make her feel more in control, 
At the moment it's totally out of my control. Totally out of my control. I've got a wonderful tissue viability nurse here, she tells me what's going on and all the rest of it, but no, think we just need to make sure, I suppose it's a confidence thing really because you lie on your side every day and have a dressing done and lie back again and not really know what's happening. I think a picture would be quite a good idea. If I could see a picture if the first one and what it is like now, whether there's a change or if I'd be disappointed I don't know (participant 12).

Patient and carer participants described loss of autonomy associated with waiting around for services, and this was sometimes exacerbated by poor communication and communication between services.

They've come at quarter to seven in the evening to put her to bed, they're coming very late in the mornings, and then they're getting mum up sometimes 10:30-11:00. ... The timing can be awful ... My sister has had numerous conversations with them. They have had times when the district nurse has arrived to do the dressing but she can't do it because mum's not out of bed and they've gone away and come back (carer of participant 7).

Participant 5 desperately wanted to remain in the paid workforce and had made major efforts to heal the PI on his heel, to facilitate his return to work. However, despite his best efforts this was unsuccessful.

I was in hospital for 5 months but when I got out of hospital I was off work for 12 months with this. ... then I just recently had 4 months off work, I figured the heel just needed a rest. I had 2 months off work and I thought to myself I've got to go and give it another go and I went back to work and I lasted 4 days, 4 half days and I had to go off again (participant 5).

Matters such as selecting clothing and home furnishings, including bedding were now no longer a simple matter of personal choice. Participant 8 yearned to be able to wear 'normal' shoes; however, this was not possible, due to his PI. 
I have to get adjustable shoes. If they really bandage it up I have a job putting my shoes on. It's a pain I can't have normal shoes. I've always been one to wear comfortable shoes, as a teenager I had heels but... Oh I like shoes. So I'm always looking at shoes as well you know (participant 8).

Participant 10 had to use a hospital bed in her own home. She longed to be able to sleep in her own bed again.

I've got my frame and a recliner chair. I've got a hospital bed that I don't like. When I lay on it a night time you can hear the squeaking of the.... It's like... you know the air I the... how can I explain it....it's like a squeaking noise. I keep hearing that all the time... I don't like the bed anyway. I wish to God I had my own bed or a different type of mattress (participant 10).

\section{DISCUSSION:}

Although there is significant literature on loss, grief and sorrow in other patient groups $(28,29)$, little attention has been given to understanding the experience and nature of loss for individuals with PI. On the whole, understanding the experiences of this patient group has been largely overshadowed by issues of health service delivery and biomedical treatments and risk factors $(5,30)$. Highlighting the limited interpretation of loss in the PI literature, a systematic review of the impact of PI upon older people conceptualised loss in terms of loss of interest in socialising, loss of independence and loss of appetite (13). This review also reported issues such as struggling to regain control and independence, self-concept, and avoidance, but these issues were not considered through the lens of loss. Similarly, three earlier studies examining patient's experiences of PI reported loss in terms of lost independence $(8,9,14)$. Though loss is acknowledged in the literature on $\mathrm{PI}$, compared to other forms of chronic illness, less attention is given to the loss associated with PI.

The theme of loss was present in many forms in all of our participant's stories. This loss was often experienced as long-term and life changing - the experience of living with a wounded body, and the 
uncertainty of recovery, eroded personal dignity, identity and independence. This loss of dignity was magnified by the loss of personal control and autonomy. There is a strong argument in the nursing literature that autonomy must be respected in order to promote patient dignity, and that a person will have the best idea of what may or may not promote their wellbeing (31). The concept of independence is fundamental to people being able to remain in their homes; indeed, older people view remaining at home as synonymous with independence (32). Our findings resonate with literature suggesting loss of independence in patients with a PI can affect self-esteem and confidence increasing likelihood of social isolation and the development of mental health issues (14, 10). Furthermore, for our participants, loss was experienced as a multifaceted phenomenon. Loss of dignity and privacy was experienced alongside grief for the loss of an uninjured body and one's associated identity and capabilities. Participants spoke primarily about notions of personal and relational dignity associated with the loss of privacy, independence and increasing fragility, which gave rise to feelings of reduced personal identity and sense of self-esteem. This form of dignity of self, refers to the dignity individuals attach to themselves as persons with a history and a future (33), along with perceptions about their personal worth and value that is reflected back through their social interactions (34). This type of loss of dignity has been recognised as a major concern in the lives of older people (35), with difficulty maintaining physical appearance and personal hygiene a threat to dignity (36).

Unlike other traumatic injuries (37), little attention has been given to understanding the challenges faced by patients with PI and their meaning-making strategies as they move forward in relationships, occupations and adaption to their injury. For participants, adaptation to their injury and loss was a struggle between holding onto their pre-injury lifestyle while and adjusting to life with a PI. The ability to cope with a chronic condition such as a PI is influenced by an individual's sense of coherence (38) and their capacity to establish a sense of normality in their life. The sense of ongoing uncertainty and risk associated with living with a PI is likely to reduce the capacity for coherence and normality. Murray (39) highlighted that when something of value is lost, grief reactions and despair 
often follow. Chronic sorrow can follow repeated losses, and this sorrow can persist for some time, or until the discrepancy created by the loss is resolved (39). Patients living with Pls are subject to multiple losses, and due to these losses they are no longer as they once were. As a consequence, they are at risk of ongoing grief and loss (40). This is likely to be exacerbated by feelings of dependency and self-conscious or critical self-appraisal, which is reported as common experience for people learning to live with debilitating chronic illness (29). In living with a PI, issues such as malodour and exudate, social isolation, reduced independence and reduced mobility functioned to reduce patient's sense of dignity and self-esteem. Employing the concept of lived body makes it possible to understand loss from the patient's perspective, particularly in terms of their wellbeing (39) and their life situation and illness journey (40).

For our study participants, the experience of a PI and its treatment and trajectory generated feelings of vulnerability and uncertainty. Faced with the stark reality that these injuries often defy healing, and the outcomes are often not what was hoped for, participant's loss was characterised by prolonged uncertainty. These findings resonate with earlier qualitative studies of spinal cord injury patients living with a PI $(8,9)$. Living in the shadow of this persistent risk and uncertainty, the nature of the loss experienced by participants in our study can be characterised as ambiguous loss (38). Ambiguous loss is defined as an unclear loss, or one that defies closure or resolution. Interventions for this type of loss are based on resilience instead of closure, finding meaning, discovering hope and reconstructing identity (41). In their struggle to maintain a sense of dignity and worth in spite of their losses, some participants in our study were sufficiently resilient to foreground their inner dignity and worth. Others felt the injury was in control of their life.

The challenges recounted by our participants of sustaining personal dignity and self-identity in the face of a life challenging, and possibly life threatening, $\mathrm{Pl}$ is similar to those reported in studies of patient dignity and control during end of life care (31). Importantly, PI is rarely framed in nursing discourses as a life-challenging or life-limiting or chronic illness (30) When PI is framed in terms of 
being "chronic", attention is given almost entirely to the technical and biomedical management of the wound or factors that promote wound healing (44). Little to no attention has been given to strategies to support patients to be in control of their $\mathrm{PI}$ as a chronic disease, and little is known about the types of supports that help establish normality and positive identity among patients with longer term PI. Notably, a recent integrative review of the literature examining resilience and living with a wound, did not identify studies of people with PI (45).

Addressing and improving the quality of life is important for people living with chronic wounds, yet little is known how care workers may inhibit or foster these behaviours. Nurses caring for patients with PI must be aware of the threat to dignity and the risk of loss and vulnerability that arise from the experience of living with a PI. Of note, qualitative studies of nurses' experiences of caring for chronic wounds, report that nurses distance themselves (5) or downplay the significance of the wounds $(8,9)$. Similarly, when dealing with patient $\mathrm{PI}$, nurses may focus their attention on the technical aspects of wound care, to maintain emotional distance in a situation which they find emotionally difficult (46). When considering that some patients' PI will not heal and they may be living with it for the remainder of that person's life (47) it is increasingly more important to involve the patient to find out what matters most to them and how their wound is impacting on them, to make a holistic, person-centred plan of care to alleviate symptoms, promote health and to increase well-being as much as possible (48).

\section{Strengths and limitations of the study}

As with all research there are strengths and limitations of this study. What this paper adds are deep insights into the experience of loss related to living with a PI in the community. The participants were all drawn form one region of the United Kingdom; this may limit the generalisability of the findings. It is also possible there may have been some selection bias as participants volunteered to 
be interviewed and the experiences of those who did not volunteer may be different to those presented here.

\section{Implications for future research}

Further research exploring how individuals adjust to PI as a chronic or life threatening condition and the associated experience of loss is warranted. Like other chronic conditions, PI may deteriorate, remit, and recur. For many patients living in the community, a defining feature of their life is that the PI will persist and they will continue to require assistance with their activities of daily living that will compound their perceived experience of loss.

\section{CONCLUSIONS:}

Findings from this study highlight the emotional effects of having a PI on our participants and reinforce the importance of hearing the patient voice when developing interventions to prevent and manage PI. Policy and practice should recognise and reflect that patients with PIs living at home have different challenges and needs to those in acute or long term care. Pragmatic solutions in the delivery of pressure injury care are needed to compliment the drive to move healthcare from the hospital to home.

\section{ACKNOWLEDGEMENTS AND DISCLOSURES:}

This work was supported by Oxford Brookes University Central Research Fund. The authors declare that they have no conflicts of interest. 


\section{REFERENCES:}

1. National Pressure Ulcer Advisory Panel, European Pressure Ulcer Advisory Panel and Pan Pacific Pressure Injury Alliance. (2014). Prevention and Treatment of Pressure Ulcers: Quick Reference Guide. Emily Haesler (Ed.). Cambridge Media: Osborne Park, Australia.

2. Landi, F., Onder, G., Russo, A., \& Bernabei, R. (2007). Pressure ulcer and mortality in frail elderly people living in community. Archives of Gerontology and Geriatrics, 44, 217-223.

3. Gould, L., Abadir, P., Brem, H., Carter, M., Conner-Kerr, T., Davidson, J., ... Schmader, K. (2015). Chronic wound repair and healing in older adults: current status and future research. Wound Repair and Regeneration, 23(1), 1-13.

4. Jackson, D., Durrant, L., Bishop, E., Walthall, H., Betteridge, R., Gardner, S., Coulton, W., Hutchinson, M., Neville, S., Davidson, P. \& Usher, K. (2017). Health service provision and the use of pressure redistributing devices: Mixed methods study of community dwelling individuals with pressure injuries. Contemporary Nurse, 53(3):378-389

5. Varga, M. A. and Holloway, S. L. (2016). The lived experience of the wound care nurse in caring for patients with pressure ulcers. International Wound Journal, 13(2), 243-251.

6. Souza, D. M. S. T. D., Borges, F. R., Juliano, Y., Veiga, D. F., \& Ferreira, L. M. (2013). Quality of life and self-esteem of patients with chronic ulcers. Acta Paulista de Enfermagem, 26(3), 283-288.

7. RCN (2013) Pressure ulcers: A guide to eliminating all avoidable grade 2, 3, and 4 pressure ulcers. RCN Publishing Company Limited, UK: St Austell Press.

8. Fox, C. (2002). Living with a pressure ulcer: a descriptive study of patients' experiences. Journal of Wound Care, 11(6), 10-22.

9. Langemo, D. K., Melland, H., Hanson, D., Olson, B., \& Hunter, S. (2000). The lived experience of having a pressure ulcer: A qualitative analysis. Advances in Skin \& Wound Care, 13(5), 225235. 
10. Hopkins, A., Dealey, C., Bale, S., Defloor, T., \& Worboys, F. (2006). Patient stories of living with a pressure ulcer. Journal of Advanced Nursing, 56(4), 345-353.

11. Elfrey, M. K., \& Ziegelstein, R. C. (2009). The "inactivity trap". General Hospital Psychiatry, 31(4), 303-305.

12. Gallagher, P., Barry, P., Hartigan, I., McCluskey, P., O'Connor, K., \& O'Connor, M. (2008). Prevalence of pressure ulcers in three university teaching hospitals in Ireland. Journal of Tissue Viability, 17(4), 103-109.

13. Gorecki, C., Brown, J. M., Nelson, E. A., Briggs, M., Schoonhoven, L., Dealey, C., ...Nixon, J. (2009). Impact of pressure ulcers on quality of life in older patients: A systematic review. Journal of the American Geriatrics Society, 57(7), 1175-1183.

14. Spilsbury, K., Nelson, A., Cullum, N., Iglesias, C., Nixon, J., \& Mason, S. (2007). Pressure ulcers and their treatment and effects on quality of life: Hospital inpatient perspectives. Journal of Advanced Nursing, 57(5), 494-504.

15. Kim, J., Ahn, H., Lyon, D.E. and Stechmiller, J. (2016). Building a biopsychosocial conceptual framework to explore pressure ulcer pain for hospitalized patients. Healthcare, 4(1), 7. https://dx.doi.org/10.3390\%2Fhealthcare4010007.

16. Coleman, S., Gorecki, C., Nelson, E. A., Closs, S. J., Defloor, T., Halfens, R., ...Nixon, J. (2013). Patient risk factors for pressure ulcer development: systematic review. International Journal of Nursing Studies, 50(7), 974-1003.

17. VanGilder, C., Lachenbruch, C., Algrim-Boyle, C., \& Meyer, S. (2017). The International Pressure Ulcer Prevalence ${ }^{\mathrm{TM}}$ Survey: 2006-2015: A 10-year pressure injury prevalence and demographic trend analysis by care setting. Journal of Wound Ostomy \& Continence Nursing, 44(1), 20-28.

18. Green, J., Jester, R., McKinley, R., \& Pooler, A. (2014). The impact of chronic venous leg ulcers: A systematic review. Journal of Wound Care, 23(12), 601-612. 
19. Galhardo, V. A., Garroni, M. M., Blanes, L., Juliano, Y., \& Masako, F. L. (2010). Health-related quality of life and depression in older patients with pressure ulcers. Wounds: A Compendium of Clinical Research and Practice, 22(1), 20-26.

20. Franks, P. J., Winterberg, H., \& Moffatt, C. J. (2002). Health-related quality of life and pressure ulceration assessment in patients treated in the community. Wound Repair and Regeneration, 10(3), 133-140.

21. Palfreyman, S., \& Mulhern, B. (2015). The psychometric performance of generic preferencebased measures for patients with pressure ulcers. Health and Quality of Life Outcomes, 13(1), 117-125. DOI: 10.1186/s12955-015-0307-4.

22. Gorecki, C., Nixon, J., Lamping, D. L., Alavi, Y., \& Brown, J. M. (2014). Patient-reported outcome measures for chronic wounds with particular reference to pressure ulcer research: A systematic review. International Journal of Nursing Studies, 51(1), 157-165.

23. Jackson, D.,Durrant, L., Bishop, E., Walthall, H., Betteridge, R., Gardner, S., Coulton, W., Hutchinson, M., Neville, S., Davidson, P. \& Usher, K. (2017). Pain associated with pressure injury: a qualitative study of community based, home-dwelling individuals. Journal of Advanced Nursing, DOI: 10.1111/jan.13370

24. Fusch, P. I., \& Ness, L. R. (2015). Are we there yet? Data saturation in qualitative research. The Qualitative Report, 20(9), 1408-1416.

25. Braun, V. and Clarke, V. (2006). Using thematic analysis in psychology. Qualitative Research in Psychology, 3(2), 77-101.

26. Koch, T. (2006). Establishing rigour in qualitative research: the decision trail. Journal of Advanced Nursing, 53(1), 91-100.

27. Usher, K. \& Jackson, D. (2014). Phenomenology, in Mills, J. \& Birks, M. eds. (2014) Qualitative methodology: a practical guide. Sage, London.

28. Ahlström, G. (2007). Experiences of loss and chronic sorrow in persons with severe chronic illness. Journal of Clinical Nursing, 16(3a), 76-83. 
29. Harrison, S. L., Robertson, N., Goldstein, R. S., \& Brooks, D. (2016). Exploring self-conscious emotions in individuals with chronic obstructive pulmonary disease: A mixed-methods study. Chronic Respiratory Disease, 14(1), 22-32.

30. Jackson, D., Hutchinson, M., Barnason, S., Li, W., Mannix, J., Neville, S., ...Usher, K. (2016). Towards international consensus on patient harm: Perspectives on pressure injury policy. Journal of Nursing Management, 24(7), 902-914.

31. Molyneux, D. (2009). Should healthcare professionals respect autonomy just because it promotes welfare? Journal of Medical Ethics, 35(4), pp.245-250.

32. Hillcoat-Nallétamby, S. (2014). The meaning of "independence" for older people in different residential settings. Journals on Gerontology: Series B, 69(3): 419-430. doi: 10.1093/geronb/gbu008

33. Rodríguez-Prat, A., Monforte-Royo, C., Porta-Sales, J., Escribano, X., \& Balaguer, A. (2016). Patient perspectives of dignity, autonomy and control at the end of life: Systematic review and meta-ethnography. PloS one, 11(3). DOI: 10.1371/journal.pone.0151435

34. Høy, B., Lillest $\varnothing$, B., Sletteb $\varnothing$, Å., Sæteren, B., Heggestad, A. K. T., Caspari, S., ... Nåden, D. (2016). Maintaining dignity in vulnerability: A qualitative study of the residents' perspective on dignity in nursing homes. International Journal of Nursing Studies, 60, 91-98.

35. Hall, S., Dodd, R. H., \& Higginson, I. J. (2014). Maintaining dignity for residents of care homes: A qualitative study of the views of care home staff, community nurses, residents and their families. Geriatric Nursing, 35(1), 55-60.

36. Fleck, C. A. (2006). Palliative dillemmas: Wound odour. Wound Care Canada, 4(3), 10-13.

37. O’Reilly, K., Wilson, N., \& Peters, K. (2017). Narrative literature review: Health, activity and participation issues for women following traumatic brain injury. Disability and Rehabilitation, 1-12. doi.org/10.1080/09638288.2017.1334838 
38. Joachim, G. L., \& Acorn, S. (2016). Living with chronic illness: The interface of stigma and normalization. Canadian Journal of Nursing Research Archive, 32(3), 37-48.

39. Murray, J. A. (2001). Loss as a universal concept: A review of the literature to identify common aspects of loss in diverse situations. Journal of Loss \&Trauma, 6(3), 219-241.

40. Boss, P. (1990). Ambiguous loss. In F. Walsh \& M. McGoldrick (Eds.), Living beyond loss: Death and the family (pp. 164,175). New York: Norton.

41. Eriksson, U., \& Svedlund, M. (2007). Struggling for confirmation-patients' experiences of dissatisfaction with hospital care. Journal of Clinical Nursing, 16(3), 438-446.

42. Hörberg, U., Ozolins, L.-I., \& Ekebergh, M. (2011). Intertwining caring science, caring practice and caring education from a lifeworld perspective-two contextual examples. International Journal of Qualitative Studies on Health and Well-being, 6(4). doi: 10.3402/qhw.v6i4.10363.

43. Boss, P. (2013). Resilience as tolerance for ambiguity. In Handbook of family resilience (pp. 285-297). New York: Springer.

44. Health Quality Ontario. (2009). Management of chronic pressure ulcers: An evidence-based analysis. Ontario Health Technology Assessment Series, 9(3), 1-203.

45. Ousey, K., \& Edward, K. L. (2014, September). Exploring Resilience When Living with a Wound-An Integrative Literature Review. Healthcare, 2(3), 346-355.

46. Bester, P., \& Van Deventer, Y. (2015). Holistic care for patients living with chronic wounds: Nursing. Wound Healing Southern Africa, 8(2), 78-81.

47. Jaul, E., 2010. Assessment and management of pressure ulcers in the elderly. Drugs \& Aging, 27(4): 311-325.

48. Brooks, M. (2013) Case study: "So much to lose" - a holistic approach to wound management. Wound Practice \& Research: Journal of the Australian Wound Management Association, 21(3), 136-140 